\title{
Expression of chemokine receptors in vernal keratoconjunctivitis
}

\begin{abstract}
Ahmed M Abu El-Asrar, Sofie Struyf, Abdulrahman A Al-Mosallam, Luc Missotten, Jo Van Damme, Karel Geboes
\end{abstract}

strategies that block CXCR3 may inhibit T lymphocyte recruitment and suppress adverse inflammatory reactions. (Br f Ophthalmol 2001;85:1357-1361)

Vernal keratoconjunctivitis (VKC) is an allergic chronic seasonally exacerbated bilateral external ocular inflammation that primarily affects children and young adults. The disease is characterised by recurrent symptoms of severe itching, photophobia, lacrimation, and discharge. ${ }^{1}$ The histopathology of VKC is characterised by infiltration of the conjunctiva by eosinophils, basophils, mast cells, $\mathrm{CD}^{+} \mathrm{T}$ lymphocytes, monocytes/macrophages, dendritic cells, plasma cells, and B lymphocytes organised as small lymphoid follicles. ${ }^{2-4} \mathrm{Re}-$ cently, several studies demonstrated that $\mathrm{CD}^{+}$ $\mathrm{T}$ lymphocytes in VKC expressed $\mathrm{T}$ helper 2 (Th2) type cytokines. ${ }^{5-8}$

The mechanisms governing the recruitment of inflammatory cells to the conjunctiva in VKC are not fully understood. Recently, a family of chemoattractant peptides, termed chemokines, has been recognised to have an important role in normal leucocyte trafficking as well as in leucocyte recruitment during inflammation. These chemokines are grouped into the CXC, CC, C, and CX3C subfamilies on the basis of the arrangement of the conserved cysteine residues. The CXC chemokines further fall into two classes depending on the presence or absence of the glutamateleucine-arginine motif (ELR) in the NH2terminal domain. The specific effects of chemokines are mediated by a family of seven transmembrane spanning G-protein coupled receptors. To date, 18 chemokine receptors have been described: receptors for the $\mathrm{CXC}$ chemokines CXCR1-5; the CC chemokines CCR1-11; the receptor for CX3C chemokine CX3CRI; and the C chemokine XCR1. ${ }^{\circ}$

In a previous report, we demonstrated increased expression of the CC chemokines, RANTES (regulated upon activation, normal T cell expressed and secreted), eotaxin, monocyte chemotactic protein (MCP)-1, and MCP-3 in the conjunctiva of patients with active VKC. ${ }^{10}$ The aims of this study were to examine the in vivo expression of chemokine receptors CCR1, CCR3, CCR5, CXCR3, and 
Table 1 Monoclonal antibodies used in this study

\begin{tabular}{lll}
\hline Primary antibody & Dilution & Source $^{\star}$ \\
\hline Anti-CCR1 (53504.111) & $1: 25$ & R \& D Systems \\
Anti-CCR3 (61828.111) & $1: 25$ & R \& D Systems \\
Anti-CCR5 (45531.111) & $1: 25$ & R \& D Systems \\
Anti-CXCR3 (49801.111) & $1: 25$ & R \& D Systems \\
Anti-CXCR3 (1C6) & $1: 25$ & BD Biosciences \\
Anti-CXCR4 (12G5) & $1: 25$ & R \& D Systems \\
Anti-CD3 (UCHT1) & $1: 400$ & Dako \\
\hline
\end{tabular}

^Location of manufacturers: R \& D Systems, Abingdon, UK; BD Biosciences, Franklin Lakes, NJ, USA; Dako A/S, Glostrup, Denmark.

CXCR4 in conjunctival biopsies from patients with active VKC and normal controls and to investigate the phenotype of inflammatory cells expressing chemokine receptors.

\section{Patients and methods}

PATIENTS

Sixteen consecutive patients with active VKC seen at the outpatient clinic of King Abdulaziz University Hospital were included in the study. The patients were 12 males and four females, with a mean age of 13.2 (SD 2.7, range 10-19) years. The symptoms mentioned by all the patients were itching, redness, photophobia, and tearing. All patients had the limbal form of the disease characterised by broad gelatinous infiltrates of the limbus. Limbal conjunctival biopsy specimens were obtained from each patient. None of the patients was on topical therapy before obtaining the biopsy. In addition, eight limbal conjunctival biopsy specimens were obtained from patients undergoing strabismus surgery without obvious inflammation and served as controls. The controls were from the same age group, and were five males, and three females. This study was approved by

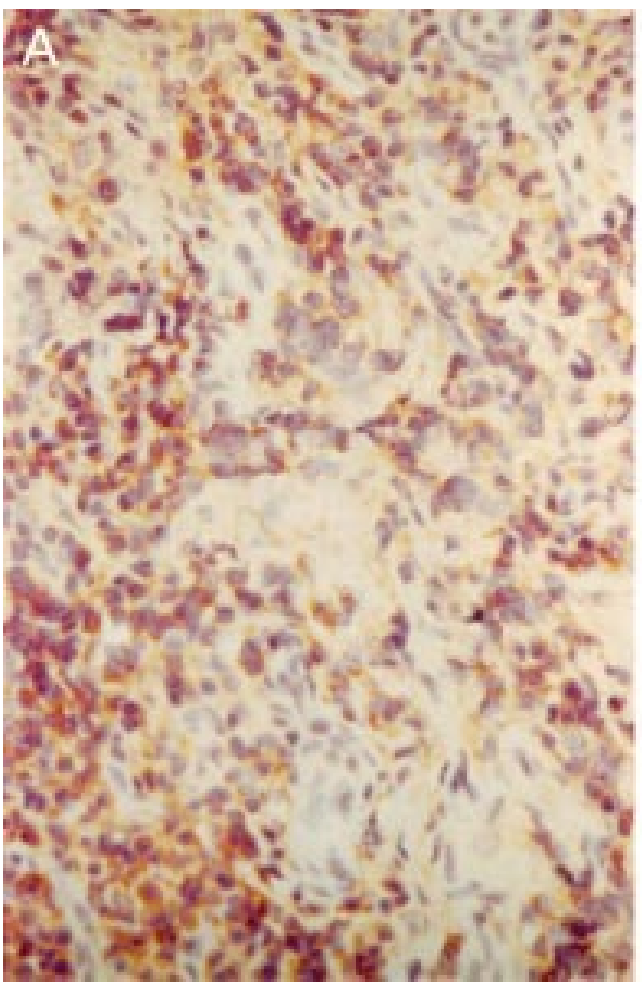

the Research Center, College of Medicine, King Saud University and the patients admitted to the study gave their informed consent.

IMMUNOHISTOCHEMICAL STAINING

The conjunctival biopsy specimens were immediately snap frozen in Tissue-Tek optimum cutting temperature (OCT) compound (Miles Laboratories, IN, USA) and maintained at $-80^{\circ} \mathrm{C}$ until use. For immunohistochemistry, $5 \mu \mathrm{m}$ serially cut cryostat sections were dried overnight at room temperature, fixed in absolute acetone for 10 minutes, and then treated with $2 \%$ hydrogen peroxide in methanol for 3 minutes to block endogenous peroxidase activity. After rinsing three times in phosphate buffered saline (PBS) at $\mathrm{pH} 7.2$ for 15 minutes, the slides were incubated for $30 \mathrm{~min}-$ utes with the monoclonal antibodies listed in Table 1. Optimal concentrations of all antibodies used were determined in pilot experiments. After a wash with PBS, the sections were incubated for 30 minutes with EnVision ${ }^{+}$, peroxidase, Mouse (Dako, CA, USA). The slides were washed again with PBS and the reaction product was visualised by incubation for 10 minutes in $0.05 \mathrm{M}$ acetate buffer at $\mathrm{pH} 4.9$, containing $\quad 0.05 \% \quad 3$-amino-9-ethylcarbazole (Sigma, MO, USA) and $0.01 \%$ hydrogen peroxide, resulting in bright red immunoreactive sites. The slides were faintly counterstained with Harris haematoxylin. Finally, the sections were rinsed with distilled water and coverslipped with glycerol.

The monoclonal antibodies used in this study (Table 1) reacted specifically with their corresponding antigens, as judged by FACS analysis using cell lines transfected with

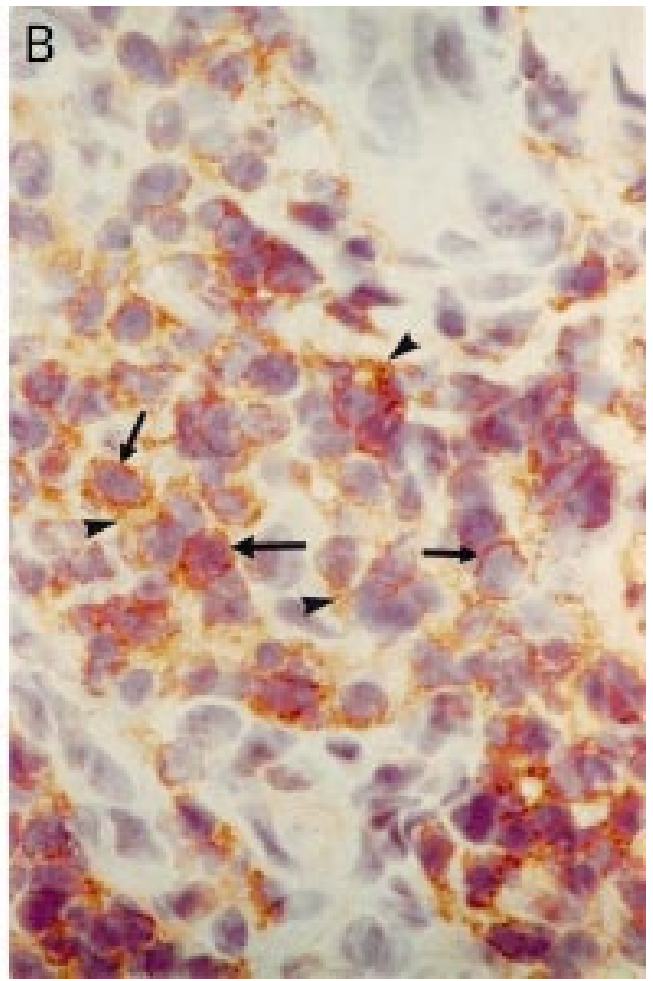

Figure 1 Vernal keratoconjunctivitis. Immunohistochemical staining for CXCR3. Low power (A) (×500) and high power (B) (×1200) views showing membranous immunoreactivity on mononuclear cells (arrows), as well as in the intercellular spaces (arrowheads). 
Table 2 Numbers ${ }^{\star}$ of inflammatory cells expressing chemokine receptors in $V K C$ and control specimens

\begin{tabular}{|c|c|c|c|c|c|}
\hline Patient No & $C C R 1$ & CCR3 & CCR5 & CXCR3† & CXCR4 \\
\hline \multicolumn{6}{|l|}{ VKC: } \\
\hline 1 & 6 & 11 & 3 & 120 & 14 \\
\hline 2 & 0 & 0 & 0 & 50 & 0 \\
\hline 3 & 0 & 0 & 0 & 45 & 0 \\
\hline 4 & 0 & 0 & 0 & 40 & 0 \\
\hline 5 & 0 & 0 & 0 & 17 & 0 \\
\hline 6 & 0 & 0 & 0 & 24 & 0 \\
\hline 7 & 0 & 0 & 0 & 125 & 0 \\
\hline 8 & 0 & 0 & 0 & 28 & 0 \\
\hline 9 & 0 & 0 & 0 & 91 & 0 \\
\hline 10 & 0 & 0 & 0 & 31 & 0 \\
\hline 11 & 0 & 0 & 0 & 31 & 0 \\
\hline 12 & 0 & 0 & 0 & 52 & 0 \\
\hline 13 & 9 & 4 & 5 & 30 & 6 \\
\hline 14 & 0 & 0 & 0 & 28 & 0 \\
\hline 15 & 7 & 3 & 2 & 87 & 8 \\
\hline 16 & 0 & 0 & 0 & 70 & 0 \\
\hline \multicolumn{6}{|l|}{ Control: } \\
\hline 1 & 0 & 0 & 0 & 0 & 0 \\
\hline 2 & 0 & 0 & 0 & 15 & 0 \\
\hline 3 & 0 & 0 & 0 & 5 & 0 \\
\hline 4 & 0 & 0 & 0 & 2 & 0 \\
\hline 5 & 0 & 0 & 0 & 2 & 0 \\
\hline 6 & 0 & 0 & 0 & 0 & 0 \\
\hline 7 & 0 & 0 & 0 & 2 & 0 \\
\hline 8 & 0 & 0 & 0 & 0 & 0 \\
\hline
\end{tabular}

VKC = vernal keratoconjunctivitis.

${ }^{\star}$ Cells counted in an area of $0.33 \times 0.22 \mathrm{~mm}$.

†Anti-CXCR3 monoclonal antibody 49801.111 .

chemokine receptors CCR1, CCR3, CCR5, CXCR3, and CXCR4 (data not shown) (Struyf et al, unpublished data). Omission or substitution of the primary antibody with an irrelevant antibody of the same species were used as negative controls.

DOUBLE IMMUNOHISTOCHEMISTRY

To examine the phenotype of CXCR3 expressing inflammatory cells, cryostat sections were studied by double immunohistochemistry. Colocalisation studies were performed in three VKC specimens. After rinsing the slides with PBS, they were incubated for 30 minutes with anti-CXCR3 monoclonal antibody 1C6 and rinsed again with PBS. Subsequently, the sections were incubated for 30 minutes with EnVision $^{+}$, peroxidase, Mouse (Dako, CA, USA) and washed again with PBS, and the reaction product was visualised by incubation for 10 minutes in $0.05 \mathrm{M}$ acetate buffer at

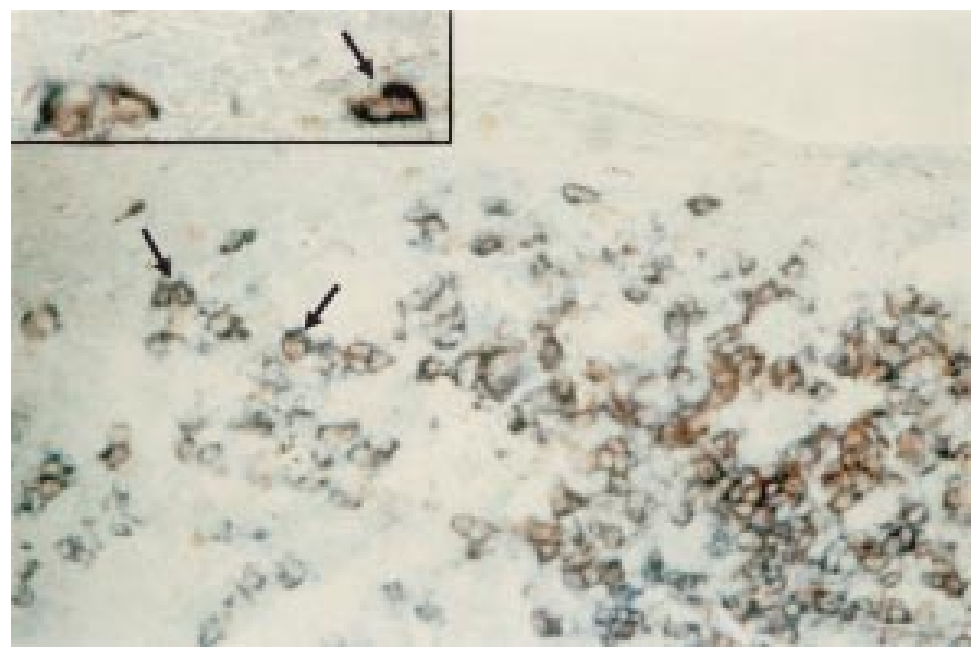

Figure 2 Vernal keratoconjunctivitis. Double immunohistochemistry for CXCR3 (red), and CD3 (blue). Low power $(\times 500)$ and high power $(\times 1200)$ (inset) views showing CXCR3 positive cells coexpressing CD3 marker (arrows).
$\mathrm{pH} \quad 4.9$, containing $0.05 \%$ 3-amino-9ethylcarbazole (Sigma) and $0.01 \%$ hydrogen peroxide resulting in red immunoreactive staining. Afterwards the sections were rinsed in PBS, washed with distilled water, and incubated for 30 minutes with the second monoclonal antibody to determine cellular phenotype (anti-CD3, Table 1). After a wash with PBS, the sections were incubated for 30 minutes with a biotin labelled rabbit antimouse antibody, followed by a monoclonal anti-biotin-alkaline phosphatase conjugate (Sigma). The blue reaction product was developed using fast blue BB salt (4-benzoylamino2.5-diethoxybenzene-diazonium chloride) (Sigma) for 5 minutes.

\section{QUANTITATION}

Cells were counted in five representative fields. We used an eyepiece calibrated grid with $\times 40$ magnification. With this magnification and calibration we counted the cells present in an area of $0.33 \times 0.22 \mathrm{~mm}$. For the co-localisation studies, cells expressing both CXCR3 and CD3 were counted and expressed as a percentage of cells expressing CD3.

All data are presented as mean (SD). The Mann-Whitney U test was used to compare the mean numbers of CXCR3 expressing inflammatory cells in VKC specimens versus controls. The differences were considered significant if the $\mathrm{p}$ value was $<0.05$.

\section{Results}

There was no staining in the negative control slides. In normal conjunctiva, few $\mathrm{CXCR}^{+}$ inflammatory cells were identified in the substantia propria in five of eight specimens with the two different anti-CXCR3 monoclonal antibodies 49801.111 and 1C6. There was no immunoreactivity for CCR1, CCR3, CCR5, and CXCR4. 
In VKC specimens, membranous immunoreactivity for CXCR3 was noted on inflammatory cells in the epithelial and stromal inflammatory infiltrate in all specimens (Fig 1). Both CXCR3 antibodies that we used generated the same labelling pattern on inflammatory cells. Furthermore, CXCR3 staining was observed in the intercellular spaces within the inflammatory infiltrate (Fig 1). Compared with controls, VKC specimens showed statistically significant more $\mathrm{CXCR}^{+}$inflammatory cells (54.3 (SD 34.3) v 3.3 (5.0); p <0.001). Few $\mathrm{CCR}^{+}$, $\mathrm{CCR}^{+}, \mathrm{CCR}^{+}$, and $\mathrm{CXCR} 4^{+}$inflammatory cells were observed in three of 16 specimens. The cell counts are presented in Table 2 .

Double immunohistochemistry to confirm the phenotype of CXCR3 positive inflammatory cells indicated that all CXCR3 positive inflammatory cells in the normal conjunction and VKC specimens (Fig 2) expressed the pan-T cell marker CD3. Moreover, the majority of $\mathrm{T}$ lymphocytes in the inflammatory infiltrate were reactive for CXCR3 (mean $61.7 \%$ (SD 3.7\%), $\mathrm{n}=3$ ).

\section{Discussion}

In the normal conjunctiva, CXCR3 was expressed on few inflammatory cells, while CCR1, CCR3, CCR5, and CXCR4 were not expressed. Our observations were consistent with previous reports that CXCR3 was expressed on normal human intestinal lymphocytes, ${ }^{11}$ and on rare cells in normal skin. ${ }^{12}$ It is suggested that CXCR3 may have an important role in lymphocyte localisation within the intestinal mucosa and contribute to the selctive recruitment of lymphocytes to the intestine. ${ }^{11}$ Compared with normal conjunctiva, the conjunctiva from patients with active VKC showed statistically significant more $\mathrm{CXCR}^{+}$inflammatory cells. CXCR3 was expressed on the majority of infiltrating $\mathrm{T}$ lymphocytes in conjunctiva from patients with active VKC, while CCR1, CCR3, CCR5, and CXCR4 were present on a minority of inflammatory cells in few specimens. CXCR3 is suggested to be a marker for $\mathrm{T}$ lymphocytes associated with certain inflammatory reactions and appears to mark subsets of lymphocytes with a capacity for migration to inflammatory sites. ${ }^{13}$ CXCR3 has been documented to be expressed on the vast majority of perivascular $\mathrm{T}$ lymphocytes in colonic biopsies from patients with ulcerative colitis ${ }^{13}$ and Crohn's disease, ${ }^{14}$ synovial biopsies from patients with rheumatoid arthritis, ${ }^{13}$ chronically inflamed vaginal mucosa, ${ }^{13}$ skin biopsies from patients with allergic contact dermatitis $^{12}{ }^{15}$ and systemic sclerosis, ${ }^{14}$ atherosclerotic lesions, ${ }^{16}$ and actively demyelinating multiple sclerosis brain lesions. ${ }^{17}$ The high expression of CXCR3 on T cells in VKC conjunctiva might be explained by upregulation by inflammatory cytokines. Recently, Jinquan et $a l^{18}$ reported that CXCR3 is expressed on CD $34^{+}$haematopoietic progenitors from human cord blood stimulated with granulocyte-macrophage colony stimulating factor (GM-CSF) but not on freshly isolated CD $34^{+}$progenitors.
CXCR3 is selectively expressed on activated $\mathrm{T}$ cells. Treatment with interleukin (IL)-2 resulted in cultures of fully responsive, CXCR3 positive T lymphocytes. ${ }^{131920}$ Naive T cells expressed only CXCR4 and CCR1, whereas the majority of memory/activated $\mathrm{T}$ cells expressed CXCR3 and a small proportion expressed CCR3 and CCR5. ${ }^{1421} 22$ These findings suggest that CXCR3 and its ligands may play a unique part in the early stages of $\mathrm{T}$ cell activation and recruitment. ${ }^{22}$ CXCR3 has been identified as the receptor for three highly potent, inflammatory/inducible ELR negative CXC chemokine agonists, interferon $\gamma(\mathrm{IFN}-\gamma)$ inducible protein of $10 \mathrm{kDa}$ (IP-10), monokine induced by IFN- $\gamma$ (Mig), and IFN-inducible T cell alpha chemoattractant (I-TAC). ${ }^{19}{ }^{23}$ These chemokines are IFN- $\gamma$ inducible and specifically chemoattract activated $\mathrm{T}$ cells through the receptor CXCR3. ${ }^{19}{ }^{23}$ I-TAC was found to be more potent and efficacious than either IP-10 or Mig in its ability to mobilise intracellular calcium and as a chemotactic factor. $^{23}$ Recently, the mouse CC chemokine 6Ckine, which is known to chemoattract $\mathrm{T}$ cells, has been identified as a new ligand for mouse CXCR3. ${ }^{24}$ The gene for CXCR3 was localised on human chromosome Xq13, which is in clear contrast with all other chemokine receptor genes, suggesting unique functions for this receptor and its ligands that may lie beyond their established role in $\mathrm{T}$ cell dependent immunity. ${ }^{20}$

$\mathrm{CD}^{+} \mathrm{T}$ helper $(\mathrm{Th})$ cells, upon antigenic stimulation, differentiate into two distinct subpopulations, each producing its own set of cytokines and mediating separate effector functions. ${ }^{25}$ Type $1 \mathrm{Th}$ cells (Th1) produce interleukin (IL)-2, tumour necrosis factor $\beta$ (TNF- $\beta$ ), and IFN- $\gamma$ and function as effectors of cell mediated immunity. Type 2 Th cells (Th2) produce IL-3, IL-4, IL5, IL-10, IL-13, and GM-CSF which are involved in B cell switching to the production of immunoglobulin E, mast cell proliferation, and eosinophil activation and recruitment. The conjunctiva from patients with active VKC showed dense infiltration by $\mathrm{CD}^{+} \mathrm{T}$ lymphocytes. ${ }^{2-4} \mathrm{Re}-$ cently, several studies demonstrated that $\mathrm{CD}^{+}$ $\mathrm{T}$ lymphocytes in VKC expressed Th2 type cytokines. ${ }^{5-8}$ VKC, therefore, is considered as a model of Th2 cell mediated disorder. Several in vitro studies reported that the CXCR3 receptor is expressed at higher levels on Th1 compared with Th2 clones, supporting the concept that IP-10, Mig, and I-TAC mobilise preferentially Th1 lymphocytes. ${ }^{21}{ }^{26}$ However, more recent studies have found that CXCR3 is highly expressed on both Th1 and Th2 oriented memory $\mathrm{T}$ cell lines in vitro as well as in both $\mathrm{Th} 1$ and $\mathrm{Th} 2$ dominated diseases in vivo. ${ }^{12-14}$ Moreover, immunohistochemistry of VKC conjunctiva showed that CXCR3 immunoreactivity was also detectable in the intercellular spaces. Similar findings were noted in allergic contact dermatitis skin and it was suggested that CXCR3 may be shed by $\mathrm{T}$ cells and serves additional findings such as chemokine subtraction from binding to membrane receptor. $^{12}$ 
In a previous study, we demonstrated an increase in the expression of RANTES, eotaxin, MCP-1, and MCP-3 in the conjunctiva from patients with VKC compared with control subjects. ${ }^{10}$ Rather surprisingly, in the present study, their corresponding receptors including CCR1, CCR3, and CCR $5{ }^{9}$ were only expressed on few inflammatory cells in three of 16 VKC specimens. The major chemokine receptor operational in eosinophils is CCR3. This receptor appears to play a central part in allergic responses, since it is not only expressed on eosinophils but also on basophils and Th2 lymphocytes, other cells central in allergic responses. ${ }^{27-29}$ CCR3 binds multiple ligands including eotaxin, RANTES, MCP-3, and MCP-4. Of these chemokines, only eotaxin signals exclusively through CCR3. ${ }^{30}$ Our finding of poor CCR3 expression might be related to blockade of the CCR3 immunoreactive epitope by the CCR3 ligands. In addition, Zimmermann et $a l^{\beta 2}$ recently demonstrated that exposure of eosinophils to the CCR3 ligands, eotaxin, and RANTES reduced surface expression of CCR3 due to $\mathrm{CCR} 3$ internalisation. RANTES was more potent and induced a longer duration of internalisation than eotaxin. CCR3 internalisation induced by RANTES and eotaxin with subsequent cellular hyporesponsiveness may provide a mechanism for chemokines to halt eosinophil trafficking in vivo since they would no longer be responsive to other chemokine gradients operating through CCR3. In contrast, eosinophils in haematopoietic organs, tissues that do not express eotaxin, would remain responsive to the induction of subsequent chemokine gradients. $^{32}$

In conclusion, we have established that CXCR3 is expressed abundantly on T lymphocytes in VKC conjunctiva. The expression of CXCR3 suggests its involvement in the regulation of lymphocyte recruitment and that neutralisation of this pathway in vivo may modulate immune cell migration within conjunctiva in VKC patients.

This work was supported in part by the Fund for Scientific Research of Flanders (FWO-Vlaanderen). Sofie Struyf is a research assistant of the FWO-Vlaanderen.

The authors thank Ms Paula Aertsen and Ms Christel Van den Broeck for technical assistance, Mr Dustan Kangave for statistical assistance, and Ms Connie B Unisa-Marfil for secretarial work.

1 Allansmith MR, Ross RN. Ocular allergy. Clin Allergy 1988;18:1-13.

2 Abu El-Asrar AM, Tabbara KF, Geboes K, et al. An immunohistochemical study of topical cyclosporine in vernal keratoconjunctivitis. Am $\mathcal{F}$ Ophthalmol 1996;121:15661 .

3 Abu El-Asrar AM, Geboes K, Al-Kharashi S, et al. Adhesion molecules in vernal keratoconjunctivitis. Br $\mathcal{f}$ Ophthalmo 1997;81:1099-106.

4 Montan PG, Biberfeld PJ, Scheynius A. IgE, IgE receptors, and other immunocytochemical markers in atopic and nonatopic patients with vernal keratoconjunctivitis. Oph thalmology 1995;102:725-32.

5 Maggi E, Biswas P, Del Prete G, et al. Accumulation of Th-2-like helper T-cells in the conjunctiva of patients with vernal conjunctivitis. I Immunol 1991;146:1169-74.

6 Leonardi A, De Franchis G, Zancanaro F, et al. Identification of local Th2 and Th0 lymphocytes in vernal conjunctivitis by cytokine flow cytometry. Invest Ophthalmol Vis Sci 1999;40: 3036-40.
7 Uchio E, Ono SY, Ikezawa Z, et al. Tear levels of interferongamma, interleukin (IL)-2, IL-4 and IL-5 in patients with vernal keratoconjunctivitis, atopic keratoconjunctivitis and allergic conjunctivitis. Clin Exp Allergy 2000;30:103-9.

8 Calder VL, Jolly G, Hingorani M, et al. Cytokine production and mRNA expression by conjunctival T-cell lines in chronic allergic eye disease. Clin Exp Allergy 1999;29: 1214-22.

9 Murphy PM, Baggiolini M, Charo IF, et al. International union of pharmacology. XXII. Nomenclature for chemokine receptors. Pharmacol Rev 2000;52:145-76.

10 Abu El-Asrar AM, Struyf S, Al-Kharashi SA, et al. Chemokines in the limbal form of vernal keratoconjunctivitis. $\mathrm{BrF}$ Ophthalmol 2000;84:1360-6

11 Agace WW, Roberts AI, Wu L, et al. Human intestinal lamina propria and intraepithelial lymphocytes express receptors specific for chemokines induced by inflammation. Eur F Immunol 2000;30:819-26.

12 Albanesi C, Scarponi C, Sebastiani S, et al. IL-4 enhances keratinocyte expression of CXCR3 agonistic chemokines. $\mathcal{f}$ Immunol 2000;115:1395-402.

13 Qin S, Rottman JB, Myers P, et al. The chemokine receptors CXCR3 and CCR5 mark subsets of T cells associated with certain inflammatory reactions. F Clin Invest 1998;101: $746-54$.

14 Annunziato F, Cosmi L, Galli G, et al. Assessment of chemokine receptor expression by human Th1 and Th2 cells in vitro and in vivo. F Leuk Biol 1999;65:691-9.

15 Flier J, Boorsma DM, Bruynzeel DP, et al. The CXCR3 activating chemokines IP-10, Mig, and IP-9 are expressed in allergic but not in irritant patch test reactions. $\mathcal{F}$ Invest Dermatol 1999;113:574-8.

16 Mach F, Sauty A, Iarossi AS, et al. Differential expression of three T lymphocyte-activating CXC chemokines by human three T lymphocyte-activating CXC chemokines by human

17 Sørensen TL, Tani M, Jensen J, et al. Expression of specific chemokines and chemokine receptors in the central nervous system of multiple sclerosis patients. $\mathcal{F}$ Clin Invest 1999;103:807-15.

18 Jinquan $\mathrm{T}$, Quan $\mathrm{S}$, Jacobi $\mathrm{HH}$, et al. CXC chemokine receptor 3 expression on $\mathrm{CD} 34^{+}$hematopoietic progenitors from human cord blood induced by granulocytemacrophage colony-stimulating factor: Chemotaxis and adhesion induced by its ligands, interferon $\gamma$-inducible protein 10 and monokine induced by interferon $\gamma$. Blood 2000 ; 96:1230-8.

19 Loetscher ML, Gerber B, Loetscher P, et al. Chemokine receptor specific for IP-10 and Mig: structure, function and expression in activated $\mathrm{T}$ lymphocytes. $\mathcal{F}$ Exp Med 1996;184:963-9.

20 Loetscher M, Loetscher P, Brass N, et al. Lymphocytespecific chemokine receptor CXCR3: regulation, chemo3696-705.

21 Sallusto F, Lenig D, Mackay CR, et al. Flexible programs of chemokine receptor expression on human polarized $\mathrm{T}$ chemokine receptor expression on human polarized T

22 Rabin RL, Park MK, Liao F, et al. Chemokine receptor responses on $\mathrm{T}$ cells are achieved through regulation of both receptor expression and signaling. F Immunol 1999; 162:3840-50.

23 Cole KE, Strick CA, Paradis TJ, et al. Interferon-inducible T cell alpha chemoattractant (I-TAC): a novel non-ELR CXC chemokine with potent activity on activated $\mathrm{T}$ cells through selective high affinity binding to CXCR3. I Exp Med 1998;187:2009-21.

24 Soto H, Wang W, Strieter RM, et al. The CC chemokine 6Ckine binds the CXC chemokine receptor CXCR3. Proc Natl Acad Sci USA 1998;95:8205-10.

25 Mosmann TR, Coffman RL. TH1 and TH2 cells: different patterns of lymphokine secretion lead to different functional properties. Anпu Rev Immunol 1989;7:145-73.

26 Bonecchi R, Bianchi G, Bordignon PP, et al. Differential expression of chemokine receptors and chemotactic responsiveness of type $1 \mathrm{~T}$ helper cells (Th1S) and Th2S. $\mathcal{F}$ Exp Med 1998;187:129-34.

27 Heath H, Qin S, Rao P, et al. Chemokine receptor usage by human eosinophils: the importance of CCR3 demonstrated using an antagonistic monoclonal antibody. $7 \mathrm{Clin}$ Invest 1997;99:178-84.

28 Uguccioni M, Mackay CR, Ochensberger B, et al. High expression of the chemokine receptor CCR3 in human blood basophils: role in activation by eotaxin, MCP-4, and other chemokines. F Clin Invest 1997;100:1137-43.

29 Sallusto F, Mackay CR, Lanzavecchia A. Selective expression of the eotaxin receptor CCR3 by human T helper 2 cells. Science 1997;277:2005-7.

30 Daugherty BL, Siciliano SJ, De Martino JA, et al. Cloning, expression, and characterization of the human eosinophil eotaxin receptor. 7 Exp Med 1996;183:2349-54.

31 Ponath PD, Quins S, Post TW, et al. Molecular cloning and characterization of a human eotaxin receptor expressed selectively on eosinophils. f Exp Med 1996;183:2437-48.

32 Zimmermann N, Conkright JJ, Rothenberg ME. CC chemokine receptor-3 undergoes prolonged ligand- 